\title{
Editorial
}

\section{Revista Educação (v. 41, n. 2, 2018)}

\author{
ANDREIA MENDES DOS SANTOS*
}

Prezados leitores:

A revista Educação apresenta, nesta edição, o dossiê "Infância e cidade: diálogos com a educação", organizado pelas Professoras Vania Carvalho de Araújo (PPGE/UFES) e Lígia Maria Leão de Aquino (PROGED/UERJ). Essa importante temática foi generosamente pensada pelas organizadoras tendo em vista que "desde o plano oculto de suas intenções às evidências de seus constrangimentos e de suas possibilidades educativas, tornando imperativo conhecer melhor a cidade e as infâncias que nela habitam", como por elas explicado na ocasião da elaboração da proposta do Dossiê. O Dossiê foi aprovado, pelo Conselho Editorial da Educação pois, trata-se de um movimento atento as várias lógicas da cidade e interface com a questão das infâncias, temática transversal à educação, cujas demandas, significações e protagonismo são a cada dia mais emergentes na sociedade contemporânea.

A educação é chamada a dialogar com as dinâmicas sociais e com as diferentes categorias geracionais nela presentes. Assim, a proposta desta edição é reunir pesquisadores de diferentes instituições educativas e campos disciplinares que se encontram mobilizados em empreender novos estudos e debates interface com a educação.

A apresentação do Dossiê é de José G. Gondra, que além de abrir o Dossiê, inaugura os debates as cidades e sobre as diferentes formas de conviver e habitá-la, tomando as especificidades e particularidades da questão geracional e as relações instáveis que se estabelecem nestes espaços, o que torna as cidades dinâmicas e em permanente construção.

Além dos oito artigos que compõem o Dossiê, esta edição conta também com a seção "Outros temas", que trata da política editorial da diversidade temática, num espelhamento das diversas produções intelectuais da área. Compreendemos que a Revista, como um espaço de divulgação científica, deve evitar o represamento dos artigos de qualidade, rigor e relevância, tornando-se um interlocutor para a construção de um mundo mais justo e mais heterogêneo. Assim, outros seis artigos organizam essa seção.

O primeiro artigo é "O desafio da mobilização institucional na formação docente", onde Patricia Meyer, Cinthia Bitencourt Spricigo, Elisangela Ferreti Manffra e Dilmeire Sant'anna Ramos Vosgerau" oferecem um ensaio decorrente de um estudo de caso que teve por objetivo examinar o desafio da mobilização institucional na formação docente a partir da atuação do setor responsável por essas estratégias no âmbito de uma universidade comunitária confessional. "Engajamento acadêmico: desafios para a permanência do estudante na Educação Superior", de Maria Inês Côrte Vitória, Alam Casartelli, Rosa Maria Rigo e Priscila Trarbach Costa analisa as implicações pedagógicas decorrentes dos processos de engajamento acadêmico. O artigo é debruçado sobre o conceito de engagement, em sua multiplicidade de significados e aspectos que o compõem e que, quando utilizado para pensar sobre o ensino superior, tem se revelado uma importante estratégia no que se refere ao acesso, permanência e redução da evasão no mundo acadêmico.

\footnotetext{
* Professora na Pontifícia Universidade Católica do Rio Grande do Sul (PUCRS). E-mail: <andreia.mendes@pucrs.br>.
} 
"A inclusão das crianças com deficiência na educação infantil: Processo em construção", cuja autoria é de Fabíola Fernanda Patrocínio Alves, é resultado de um estudo teórico cujo foco é a discussão sobre a inclusão das crianças com deficiência na Educação Infantil. O artigo apresenta importantes considerações sobre o conceito de infância, sinalizando que a deficiência é uma experiência que institui singularidades no modo como a criança vivencia sua infância. Além desta importante consideração, a autora aborda ainda a constituição do campo da Educação Infantil, perpassando uma identidade relacionada com assistencialismo à etapa da Educação Básica. Por fim, contextualiza a educação especial na perspectiva da educação inclusiva, apontando os desafios relacionados à inclusão das crianças com deficiência no âmbito da creche e pré-escola.

Em "O ensino de Filosofia da Educação e as noções de bons encontros, acontecimento e superfície", Fernanda Mota nos apresenta considerações sobre as noções de bons encontros, acontecimento e superfície no âmbito da filosofia da educação. O texto é fruto de uma pesquisa de caráter bibliográfico a partir de autores contemporâneos e estudos posteriores feitos por estudiosos sobre as ideias destes autores. Como fundamentação teórica, a autora adota autores como: Scruton, Deleuze e Guattari, Deleuze, Foucault e Pagni, dentre outros.

"Brasil e Uruguai: influências e aproximações no campo intelectual educacional", cujos autores são Eduardo Arriada, Caroline Braga Michel e Gabriela Medeiros Nogueira, é pautado no campo da história da educação. Os autores discutem os itinerários de formação dos intelectuais de Pelotas, cidade ao sul do Rio Grande do Sul, as redes de sociabilidades e a influência de autores uruguaios nas suas formações. Trata-se de um interessante texto que retoma o início do século XX, palco de acirradas disputas ideológicas no campo educacional, contextualizando as realidades no Brasil e no Uruguai.

Ainda, em "Docência na prisão: relação professor/aluno e identidade docente", Alisson José Oliveira Duarte e Helena de Ornellas Sivieri-Pereira buscaram descrever como a relação do professor com seus alunos, em situação de privação de liberdade, pode influenciar na maneira pela qual o professor constitui sua autoimagem, autoestima e realização profissional. Através de pesquisa empírica com cinco professores da educação escolar de uma instituição prisional e com a diretora da escola, que foram entrevistas, além do uso de diário de campo, os autores identificaram a importância da relação professor/aluno no processo de constituição da identidade profissional dos professores da unidade prisional pesquisada.

Por fim, somos gratos pela confiança dos autores que submetem seus trabalhos à nossa revista. Desejamos boa leitura!

Andréia Mendes dos Santos

Editora

Pontifícia Universidade Católica do Rio Grande do Sul (PUCRS),

Porto Alegre, Rio Grande do Sul, Brasil

\footnotetext{
Organizadoras do Dossiê

VANIA CARVALHO DE ARAúJO

Universidade Federal do Espírito Santo (UFES)

Vitória, Espírito Santo, Brasil

Ligia MARIA LEÃo DE AQUiNo

Universidade do Estado do Rio de Janeiro (UERJ)

Rio de Janeiro, Rio de Janeiro, Brasil
} 